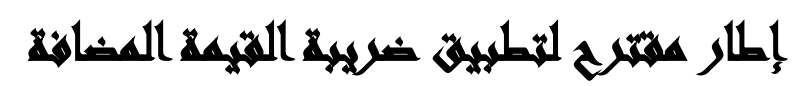

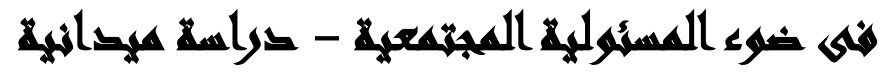

[rr]

محمد أحمد على أحمد(')- طارق عبد العال حماد(؟)- محمد عبد العزيز خليفه(؟)

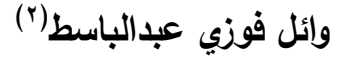

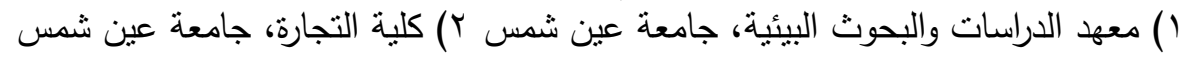

\section{المهربلهي}

استهدفت الدراسة قياس أثر تطبيق ضريبة القيمة المضافة على المسئولية المجتمعية

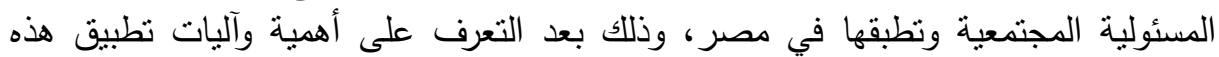

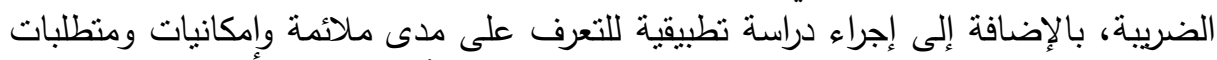

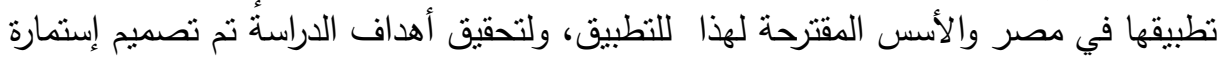

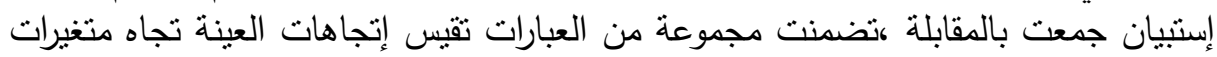

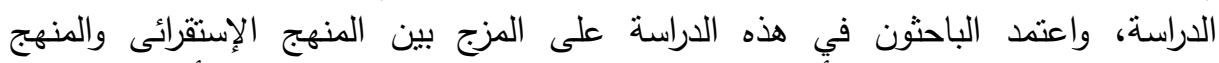

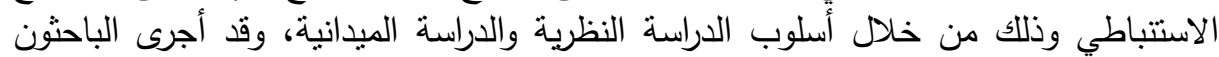

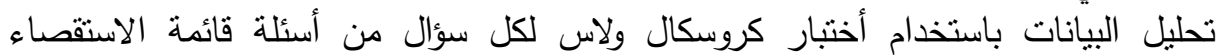

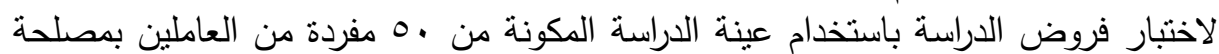

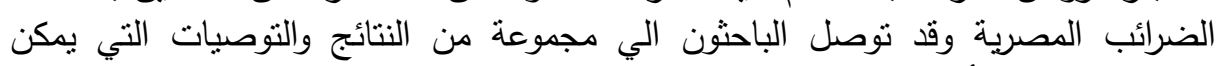

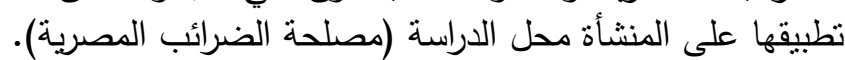
توصلت الاراسة إلى: أن هناك فوائد اقتصادية مترتبة على تطبيق الضريبة على الضى القيمة

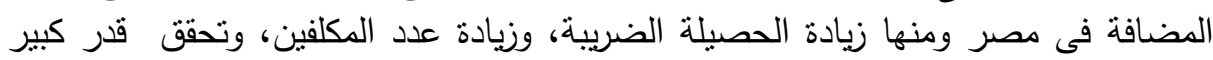

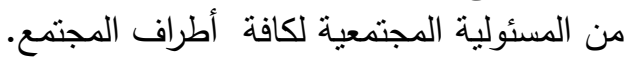
توصيات الدراسة: يوصى الباحثون بضرورة إجراء مراجعة شاملة لمواد القانون ولائحته التتفيذية كل خمس سنوات على الأقل حتي نواكب المتغيرات الإقتصادية والإجتماعية

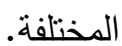

إصدار قانون موحد للإجراءات الضريبية حيث أن هناك حاجة إلى توحيد الإجراءات بين

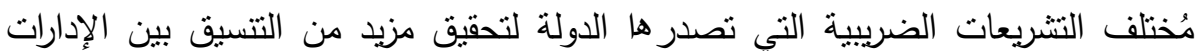
الضريبية المختلفة. 


\section{xasadl}

نظراً لأهمية السياسة الضريبية ودورها الهام والحيوى في إطار أهدافها لكلاً من

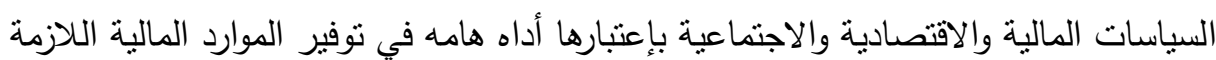

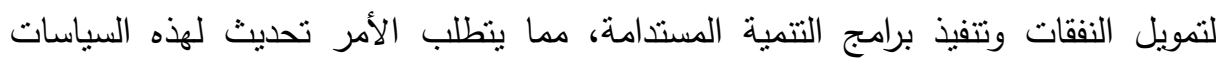
لمواكبة المتغيرات والمستجدات الأقتصادية والمالية والإجتماعية على كافة المستويات المحلية

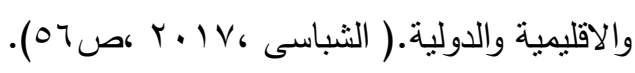

وتعتبر الضريبة على القيمة المضافة هى أحدث ما توصل إليها الفن الضريبى، وظهرت

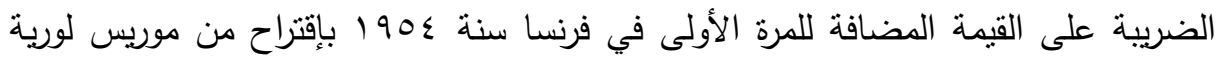

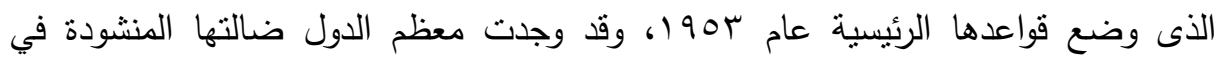
الضريبة على القيمة المضافة فأولتها أهمية كبرى، بل أصبحت هذه الضريبة في غالبية هذه

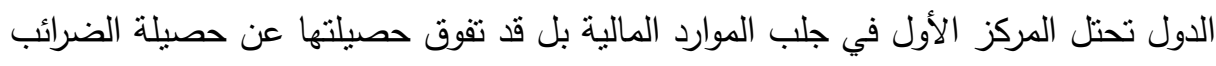

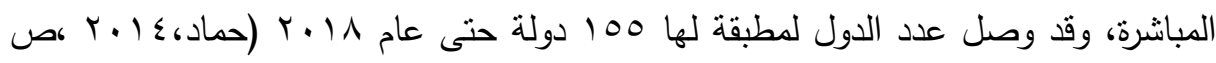

هذا ما حدا بالدول النامية إلى التطلع إلى دراستها والتحقق من مدى إمكانية تطبيقها، وهوما أكده خبراء الضرائب فى الدول العربية الأعضاء فى مجلس الوحدة الإقتصادية العربية

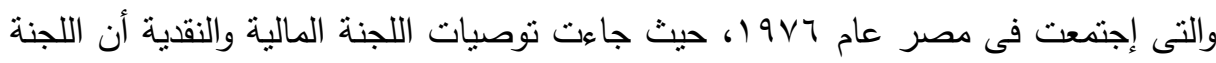
ترى فى هذه المرحلة من مراحل التنسيق الضريبى التركيز على دراسة بعض أنواع الضرائب

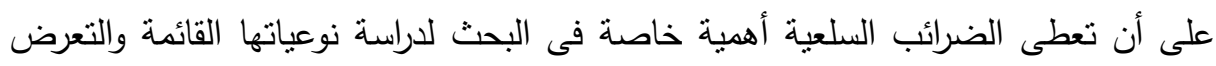

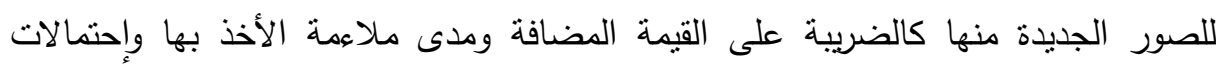
نجاحها نظراً لما يتردد كثيراً حولها.

لذا اتجهت كثثر من الدول الأجنبية ومنها فرنسا وإنجلترا والصين والعربية مصر وتونس والأردن والأمارات إلى تطبيق الضريبة على القيمة المضافة. 
ويتطلب تطبيق الضرائب بصفة عامة، وضريبة القيمة المضافة بصفة خاصة تشجيع

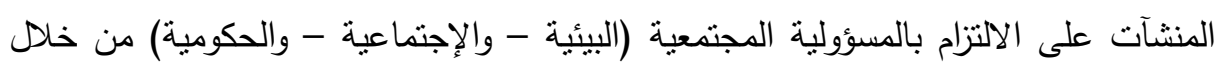
خصم الضريبة على المدخلات أو ردها عند التصدير •

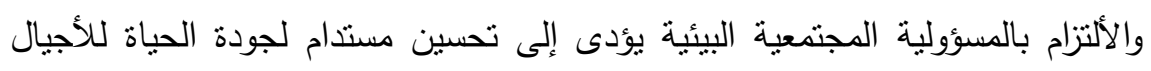

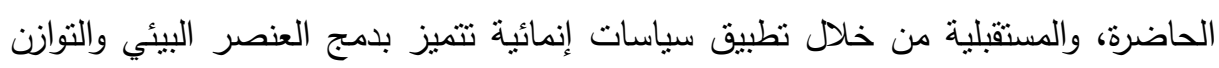

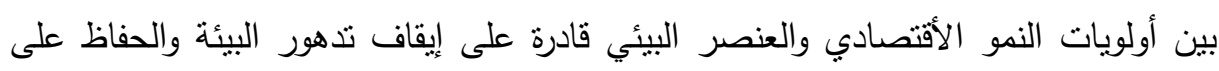

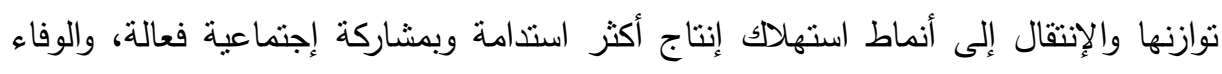

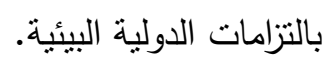

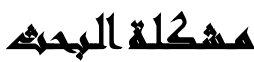

تعثبر الضريبة على القيمة المضافة أحدث ما وصل إلية المجال الضريبى، وقد قررت

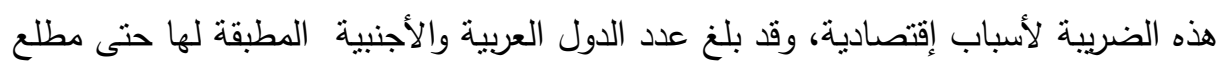

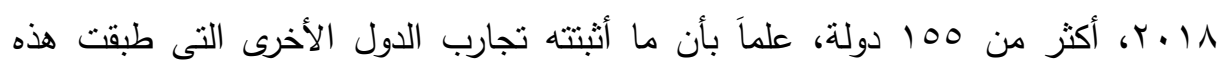

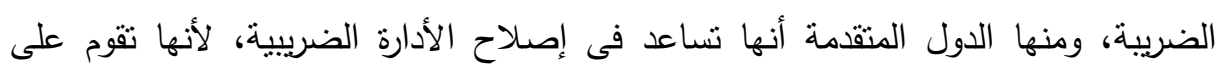

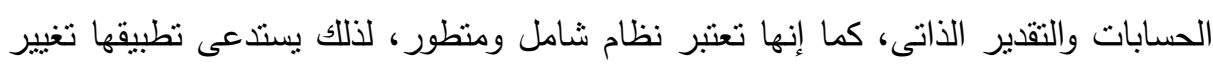
فى فلسفة الإدارة الضريبية فى مصر، كما تتميز هذه الضريبة بقدرتها على زيادة الحصيلة

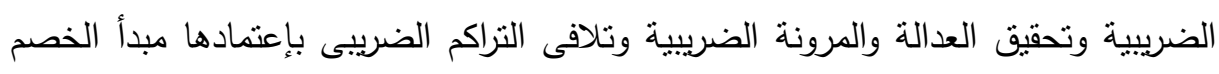

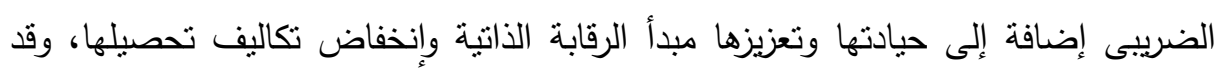
تنين وجود إختلاف فى الأنظمة الضريبية على القيمة المضافة فى الدول العربية والأجنبية

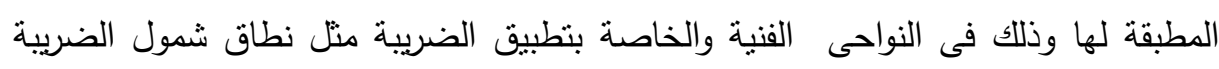

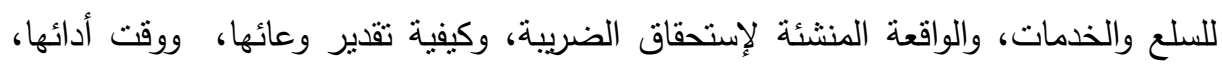

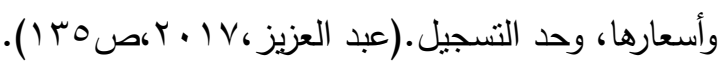

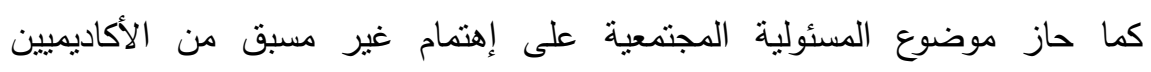

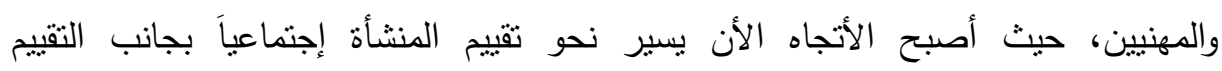
الأقتصادى، فلذلك يجب أيضاً الأخذ فى الإعنبار مساهمتها فى معالجة مشكلات المجتمع.

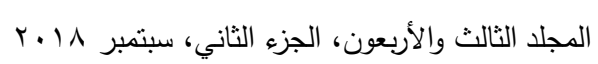


فالمسئولية المجتمعية أصبحت مؤشراً هاما لاستمرار البشرية وتحقيق التتمية المستدامة، كما أصبحت الأبعاد المتتلفة للتتمية المستدامة تمثل أولوية من أهم الأولويات على جدول

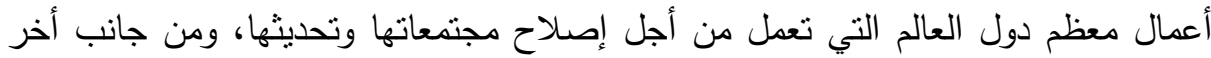
تغلغلت مسألة المسئولية المجتمعية إلى عدد من المشاكل العالمية المتداخلة أهمها الفقر، عدم

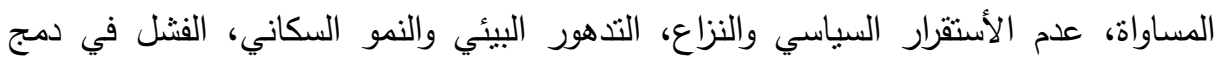
الاستدامة في سياسة التتمية وممارستها، ومن ثم فإن هناك حاجة ماسة إلى مزيد من الفهم

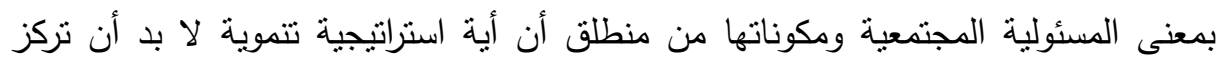

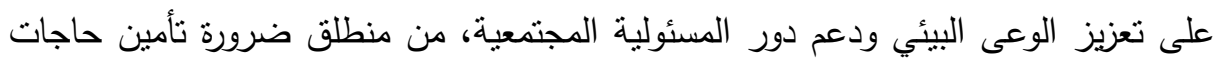
الأجيال الحاضرة بدون الإنقاص من إحتباجات الأجيال القادمة، ولن يتحقق ذلك إلا من خلال

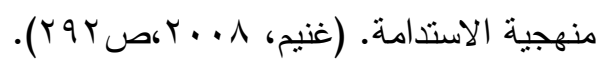
كما أن تعد المسئولية المجتمعية للشركات التزام أخلاقى بين المنظمة والمجتمع، حيث

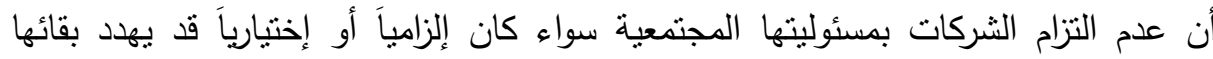
وأستمرارها لأن المنظمة تؤثر وتتأثر بالمجتمع الذى تعيش فيه.

\section{أسئلة الىراسة}

ما أثز تطبيق ضريبة القيمة المضافة على المسئولية المجتمعية؟ وينبثق من هذا التسأؤل الرئيسى التساؤلات الفرعية التالية: • كيف يمكن استخدام ضريبة القيمة المضافة في تشجيع الثركات على الالتزام بمنطلبات البيئة والمسئولية المجتمعية؟

• ما هو دور دول العالم المنقدمة للربط بين المسؤولية المجتمعية وضريبة القيمة المضافة ؟

ما ما اكانية نطبيق الضريبة علي القيمة المضافة المقترحة لتحقيق المسئولية المجتمعية؟ • ما امكانية تطبيق الضريبة علي القيمة المضافة لتحقيق التتمية المستدامة؟ • ما موقف الأصول والمستلزمات المستخدمة في قبام الشركة بالالتزام بالمسؤولية الاجتماعية؟ 
هل يسرى عليها الخصم والاسترداد، خاصة وإنها ترتبط بنمو المبيعات بشكل غير مباشر نئر نتيجة السمعة الحسنة التي تكتسبها الثركة؟ ما هو أنز تطبيق ضريبة القيمة المضافة على معالجة الأصول البيئية والمستلزمات

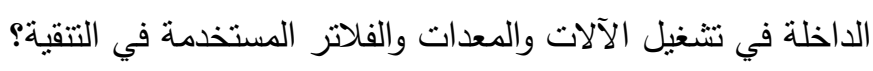
هل يجوز خصمها من الضريبة المحصلة على المخرجات منل المستلزمات الداخلة في

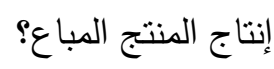

\section{أهساهي الصواهد}

يتمثل الهدف الرئيسى للبحث فى محاولة تطبيق الضريبة على القيمة المضافة في مصر فى ضوء المسئولية المجتمعية، ويتم ذلك من خلال النقاط الفرعية التالية: تحليل الجوانب النظرية والفنية للضريبة على القيمة المضافة والتفرقة بينها وبين ضرينة فينة

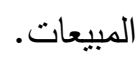
عرض وتحليل الجوانب النظرية و للتراث الفكري للمسئولية المجتمعية ودورها في تحقيق التنمية المستدامة. تحليل أهم المشكلات الناتجة عن تطبيق الضريبة على القيمة المضافة في مصر في ضوء المسئولية المجتمعية إجراء دراسة تحليلية لكيفية تطبيق الضريبة على القيمة المضافة مقارنة بتجارب الدول

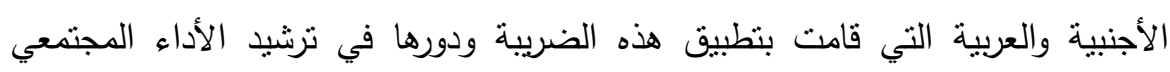
والبيئي. • التعرف على بعض النماذج الناجحة في بعض الدول التي طبقت الضربية على القيمة المضافة "إنجلترا و فرنسا، ومقارنتها مع مصر .

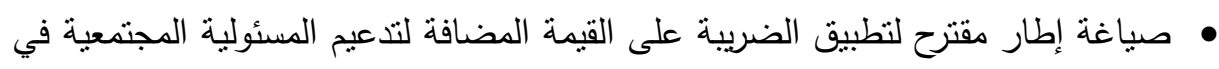




\section{أهمية الصواسمة}

تتمثل أهمية الدراسة فى جانبين الجانب العلمى (الأكاديمى) والجانب العملى (التطبيقى) الأهمية العلمية للاراسة: تتمنل أهمية البحث من الناحية العلمية فى الموضوع الذى يتتاوله البحث حيث يتم التعرض لموضوعاً معاصراً، فهنالك ندرة فى عدد الدراسات السابقة

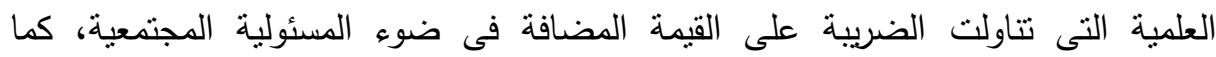

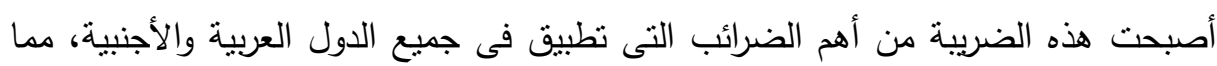
تحققة من زيادة فى الحصبلة الضريبية. الأهمية العلمية للاراسة: نتبثق أهمية البحث من مدى ما يمكن استتناجه من مؤشرات

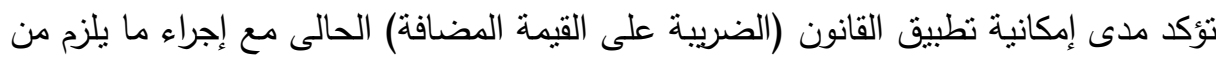
تعديلات تتفق مع الأفكار الضريبة المتطورة لتطبيق الضريبة على القيمة المضافة،والتى تعكس أفضل الصور للنهج الضريبى فى فرض الضريبة على القيمة المضافة والتى تؤدى بدورها إلى معالجة مشكلات أثز الإختلاف بين معايير المحاسبة المصرية والمعالجة الضريبية

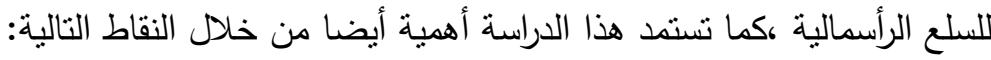

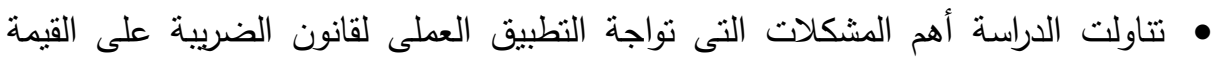

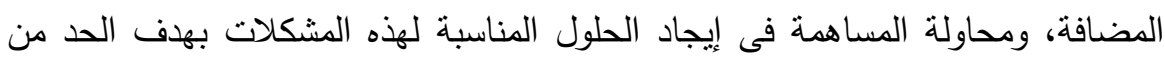
الأثار السلبية كعلاج للتطبيق. • تقديم دراسة تطبيقية بهدف تعديل بعض النصوص الضريبية المتعلقة بالضريبة على القيمة المضافة بما تحقق المسئولية المجتمعية.

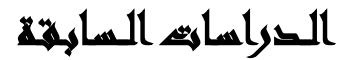

قام الباحث بتتاول أهم الدراسات السابقة العربية والأجنبية الدتعلقة بمشكلة الدراسة فى ضوء ما توافر لها وذلك على النحو التالى: 
أولاًا: الاراسات العربية: الدراسات العربية المتعلقة بالضريبة على القيمة المضافة:

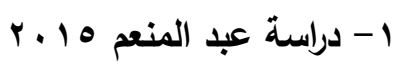

هدفت الدراسة إلي: معرفة التأثيرات المالية والأقتصادية لإحلال الضريبة على القيمة المضافة محل ضريبة المبيعات. توصلت الاراسة إلي مايلى: إلى بيان التأثز المالى والأقتصادي لتطبيق الضريبة على القيمة المضافة ومزاياه و أثشارات إلى أهم السلبيات وأوضحت أثثر الضريبة على الاسعار والأجور

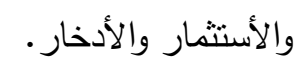

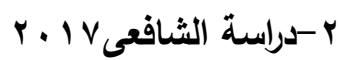
هافت الدراسة إلي: إجراء دراسة تحليلية إنتقادية للضريبة على القيمة المضافة بالقاء الضوء

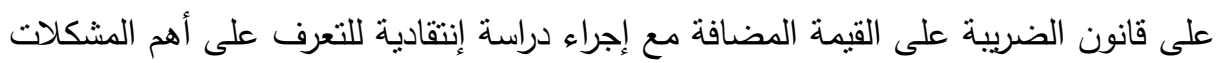
في التشريع والتطبيق

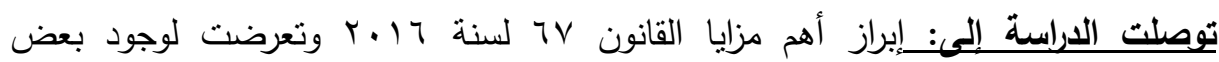
المشكلات والأنتقادات التى قد تعرقل من نجاح القانون.

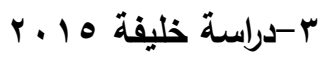

هدفت الدراسة إلىى: معرفة طبيعة وأهمية الضريبة على القيمة المضافة ونطاق تطبيقها. توصلت الدراسة الحي: أهمية الأخذ بنظام الضريبة على القيمة المضافة مع الأخذ في الأعتبار بعض الإشكاليات التى تترتب على تطبيقها. الاراسات الأجنبية المتعلقة بالضريبة على القيمة لئبة المضافة: :McIure :2011 ( 1 هدفت هذه الدراسة إلىى: أن إدخال الفيدرالية لضريبة القيمة المضافة في أمريكا يخلق

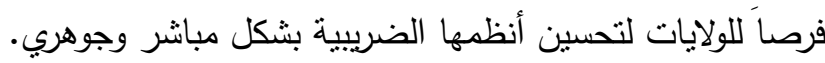

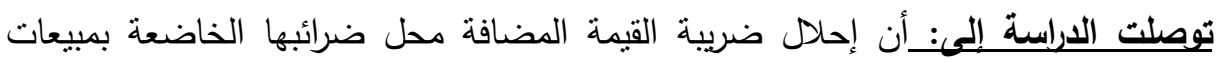
التجزئة، أو بإصلاح ضريبة مبيعات التجزئة،يساهم فى تحسين الوضع الإقتصادى للاولة. 


\section{: ZABOV.2012 براسة}

هدفت الدراسة إلىى: إجراء دراسة مقارنة بين ضريبة المبيعات البنسلفانية وضريبة القيمة المضافة البلغارية من حيث وعاء الضريبة، والمعدلات المطبقة، والإستبعادات من ضريبة المبيعات، وطريقة الأئنمان، والفاتورة المستخدمة في الضريبة على القيمة المضافة. توصلت الدراسة إلىى أن بالرغم من وجود أختلاف بين هياكل ضريبة المبيعات وضريبة القيمة

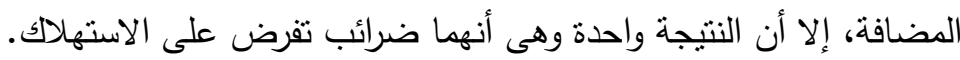

Jenkins andet., al. 2013 ( $r$ هدفت هذه الاراسة إلىى: أن الضريبة على القيمة المضافة، كغيرها من الضرائب على

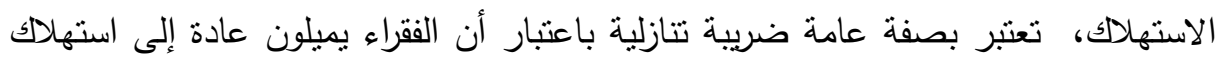
نسبة أكبر من دخلهم في الإنفاق على السلع بالمقارنة بأصحاب الاخول المرتفعة. توصلت الدراسة إلىى: أن العبْ الجاري للضريبة على القيمة المضافة في هذه الدولة كان متصاعدا لمختلف مستويات نفقات الأسر . الاراسات المتعلقة بالمسئولية المجتمعية:

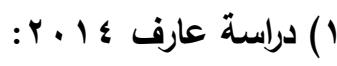
هدفت هذه الدراسة إلىي: توضيح مفهوم المسؤولية المجتمعية ومجالاتها وأسباب تزايد الاهتمام بها ومبادئها وكيفية الإفصاح عنها وأنواع الإفصاح عنها وتجارب بعض نوضيه الدول في مجال الإفصاح عن المسؤولية الاجتماعية.

توصلت الدراسة إلى: إطار مقترح لزيادة فعالية الإفصاح عن المسؤولية المجتمعية من خلال تقرير يتضمن المؤشرات البيئية والمؤشرات الاجتماعية والمشاركة المجتمعية.

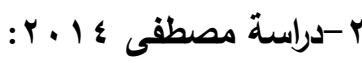
هدفت هذه دراسة إلىى: تقييم العلاقة بين المسؤولية المجتمعية للشركات وأدائها المالي وأثر

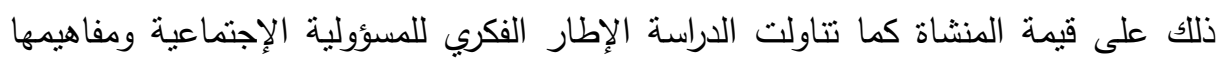
ونظرياتها وطرق قياسها والإفصاح عنها. 


\section{وتوصلت الاراسة إلىى عدة نتائج أهمها:}

إختلاف تأثثر المسؤولية الأجتماعية على الأداء المالي بإختلاف القطاعات.

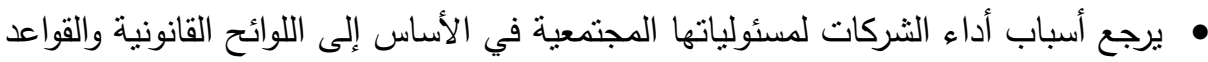

التنظيمية.

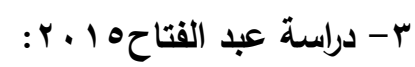

هدفت الاراسة إلىى: قياس أثز ممارسات المسؤولية الاجتماعية على الأداء المالي للمنشآت في مصر توصلت الدراسة إلىى: أن هناك علاقة إيجابية بين المسؤولية المجتمعية والأداء المالي والضريبى في مصر الاراسات الأجنبية المتعلقة بالمسئولية المجتمعية:

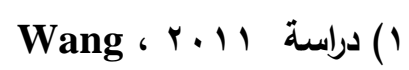

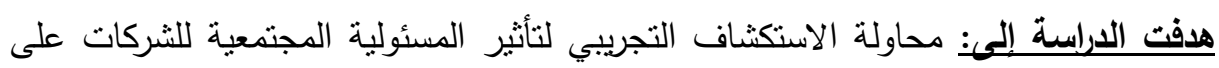
أداء الأسهم. هدوت. توصلت الدراسة إلىى: أن التزام الثركات بمسئولياتها المجتمعية له نأثثر إيجابي على أداء

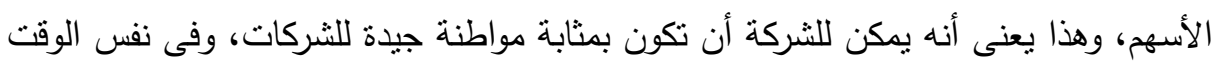
تسعى لنمو ثروة المساهمين.

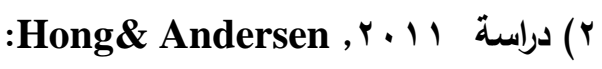

هدفت الدراسة إلىى: استكثاف العلاقة بين المسؤولية المجتمعية للشركات وربحيتها.

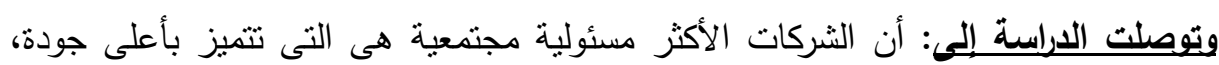
كما تزيدمن ربحيتها.

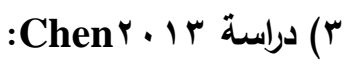
هدفت هذه الدراسة إلىى: نباين تأثثر أنشطة المسؤولية المجتمعية للشركات على الأداء النتغيلي في الثركات التايوانية. توصلت الدراسة إلى: أن المؤسسات التي تحتل ترتيبا متقدما في الاضطلاع بمسئولياتها المجتمعية لها تأثنير جوهري على كفاءتها.

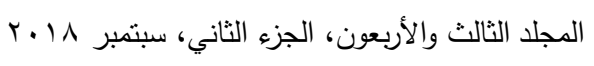




\section{الإطار اللزغليه}

تشمل الدراسة على عدد من المفاهيم التي لابد من توضيحها وتحديد المقصود منها وهي

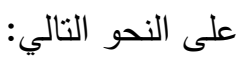
1 - تعريف الضريبة على القيمة المضافة: على إنها ضريبة غير مباشرة تفرض على السلع والخدمات يتحمل عبئها المستهلك النهائي، وهى تتذذ القيمة المضافة للمنتج أو عئه

الخدمة. ( Caldwell 2013,pp147)

وأضاف أخر: أن الضريبة على القيمة المضافة هى ضريبة غير مباشرة تفرض على السلع

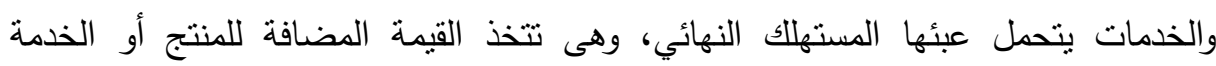

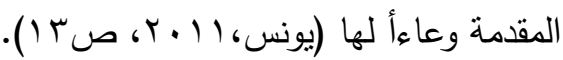

وتتمثل القيمة المضافة علي مستوى منشأة معينة في الفرق بين ثمن يبع السلعة أو الخدمة التي تقدمها هذه المنثأة، وثمن شراء المواد والخدمات الداخلة في إنتاجها وتسويقها، لعناه وبعنى أخر، فإن القيمة المضافة لأي منشأة عبارة عن الفرق بين قيمة مدخلاتها ولئه وقيمة مخرجاتها. وإذا تم تجميع القيمة المضافة لكل المنشأت على المستوى القومي، فإننا نصل إلي القيمة المضافة الكلية للمجتمع، أو ما يعرف بالناتج المحلي الإجمالي.

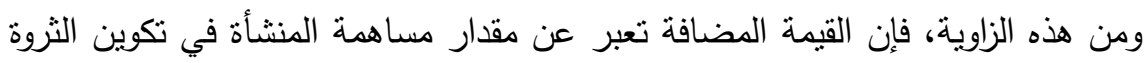

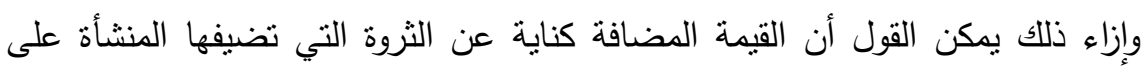
سلعة أو خدمة معينة نتيجة مزاولتها نشاط إقتصادي معين بحيث تصبح قيمة السلعة أو أو الوناه الخدمة الجديدة مختلفة عن سابقتها. وتسرى الضريبة على القيمة المضافة منشأة على حدة، فهى تحمل عند جميع مراحل

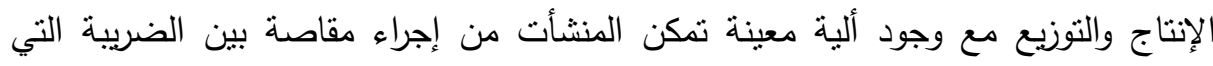

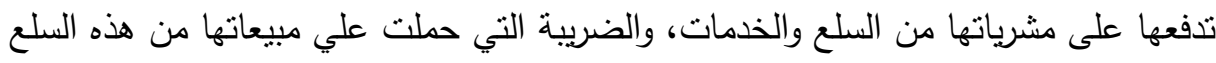
والخدمات.(Caldwell 2013,pp147) 
r- المسئولية المجتمعية :عرفها مجلس الأعمال العالمى للتتمية المستدامة :أن

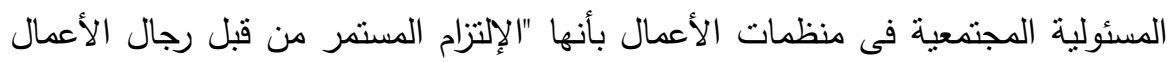

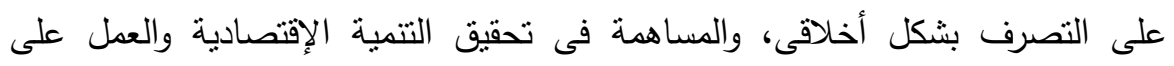

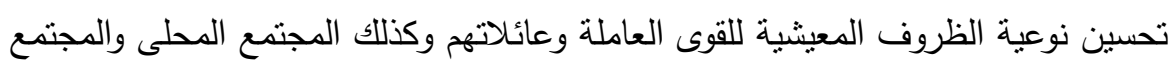

ككل.(WOrid Business ,1999).

ץ- تعريف البتك الدولي للمسؤلية المجتمعية: والذي يعرفها على أنها ” التزام

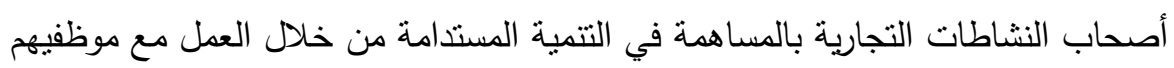

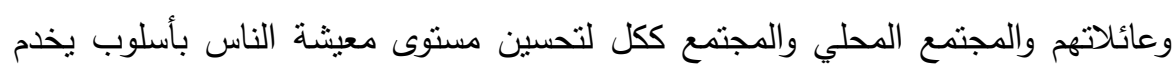

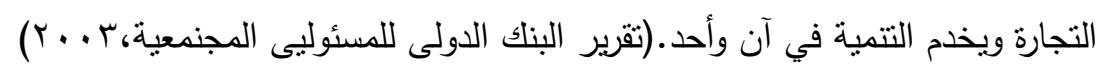

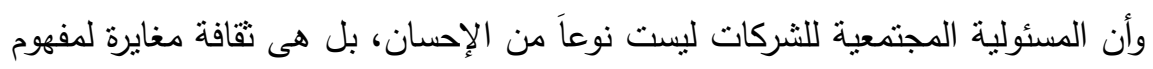

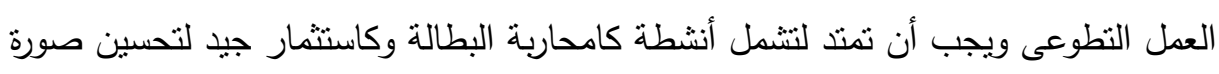

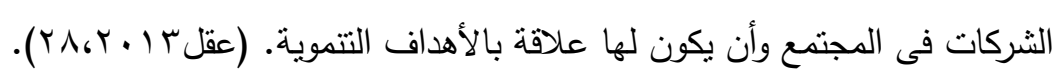

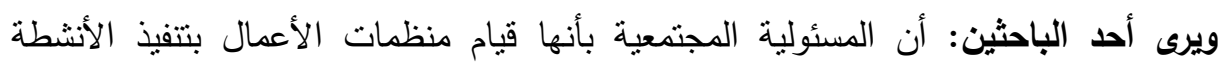

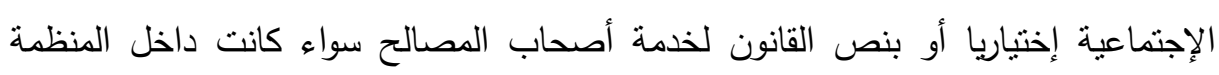

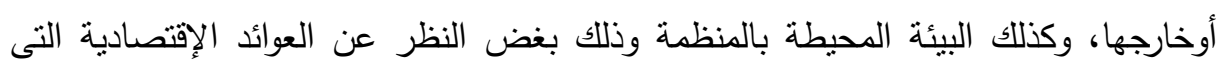

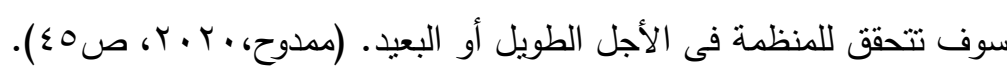

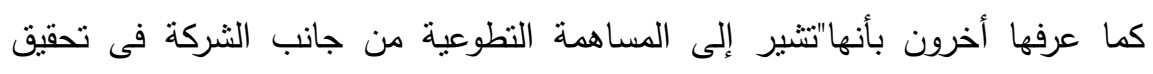

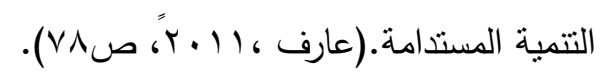

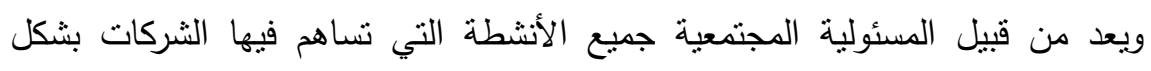

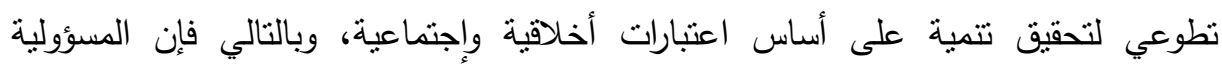

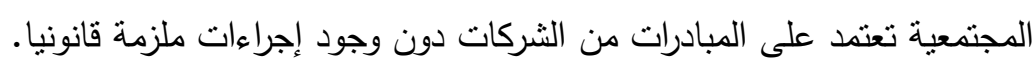

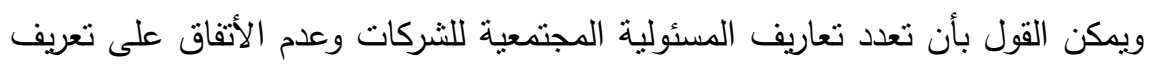

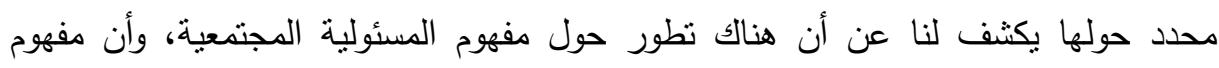

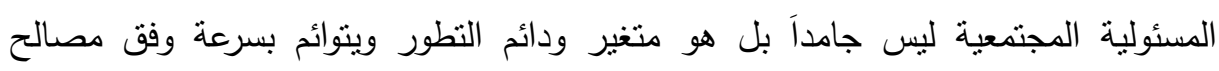

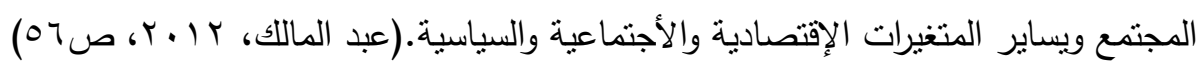

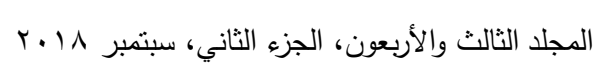




\section{هنهمج الصواسة}

فى ضوء طبيعة المشكلة وهدف وأهمية الدراسة أعتمد الباجث على منهجين أساسيين فى أعداد الدراسة هما:

المنهج الوصفي التحليلي: حيث قام الباحث بالإطلاع وإستقراء الدراسات العلمية التى تتاولت موضوع الدراسة من خلال إتباع أسلوب الدراسة المكتبية والإطلاع على المراجع العلمية المتخصصة العربية والأجنبية من كتب علمية ومقالات منشورة بالمجلات العلمية

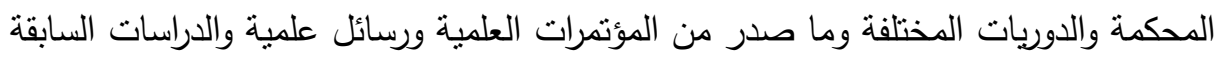

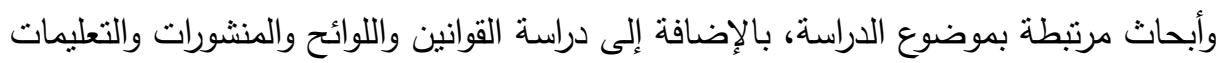
التتفيذية لقانون الضريبة على القيمة المضافة الصادرة عن مصلحة الضرائب المصرية بلهية المتعلقة بالمشكلة موضوع الدراسة.

المنهج التطبيقى: استخدم الباحث هذا المنهج بهدف الكثف عن النتائج المنطقية المترتبة على اختبار الفروض الأساسية للدراسة، وذللك من خلال القيام بدراسة ميدانية تهدف إلى

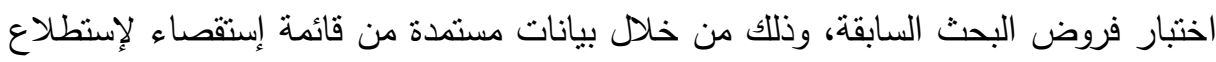
الرأى نم توزيعها على الموظفين والمديرين بمصلحة الضرائب على المبيعات.

\section{هـروضر التوراسمة}

من أجل تفسير إثكالية البحث ومحاولة الإجابة عن الأسئلة المطروحة يمكن صياغة

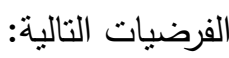
الفرض الأول: لا نوجد علاقة ذات دلالة إحصائية بين أبعاد ضريبة القيمة المضافة وأبعاد المسئولية المجتمعية.

\section{إجراعاهي التوراسلا}

الاراسة الميانية(المنهج التحليلي): عد الباحثون في إجراء الدراسة الميدانية على قائمة الاستقصاء والتي تم توزيعها على عينة من المديرين والعاملين بمصلحة الضرائب على إلى 


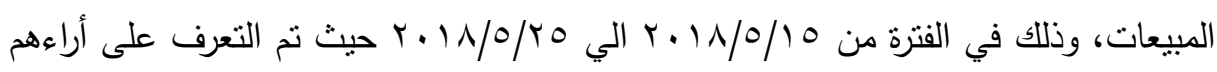
ورغباتهم واتجاهاتهم والعناصر الغير مرضية التى تواجههم وانطباعاتهم واقتراحاتهم، وقد نم استخدام الأساليب الإحصائية في تحليل البيانات والمعطيات التي نم جمعها.

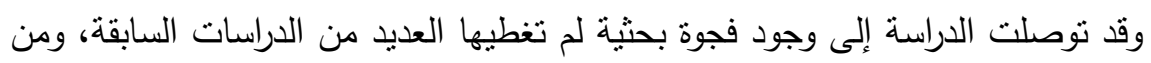

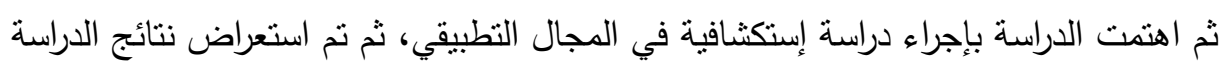

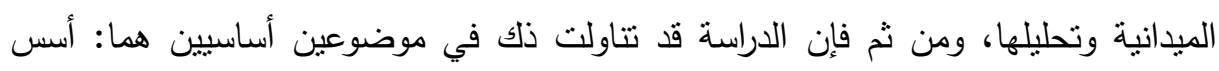

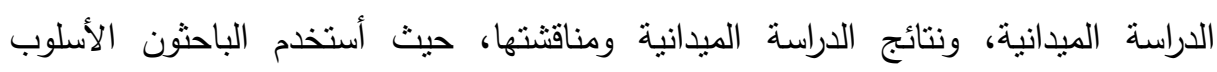
الإحصائي الأنسب للتحليل، وهو أختبار كروسكال ولاس، ولما كانت البيانات قد جاءت التهات

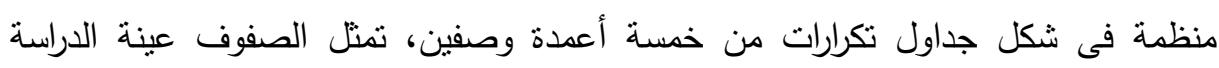
(المديرين والموظفين فى الضرائب على المبيعات) وتمثل الأعمدة استجابات الأفراد على أسئلة الاستقصاء والتى نم ترتيبها تتازلياً من موافق تماماً إلى لا أوافق مطلقاً.

\section{أسلوبي والتوايت التراسما}

ا ـ مجتمع الدراسة والعينة: بمكن توضيح كلاً من مجتمع وعينة الدراسة كما يلي:

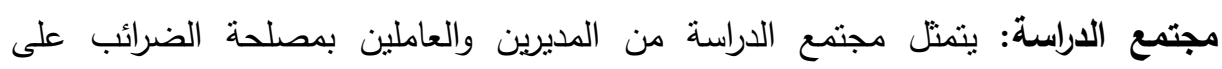
المبيعات عينة الدراسة: كانت عينة الدراسة المكونة من .0 فرداً بمثلون عينة الدراسة "وهى عدد

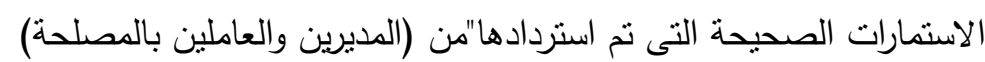

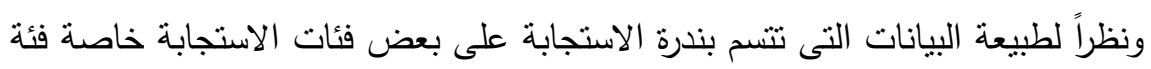

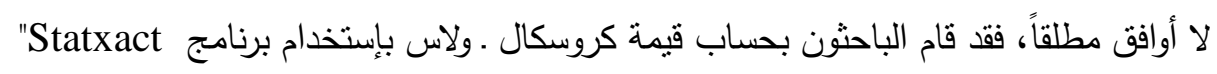
4.0 ونم اختبار معنوية قيم كروسكال ـولاس لكل سؤال عند مستوى 0 .., ..

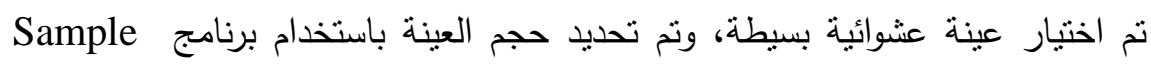
Size Calculator

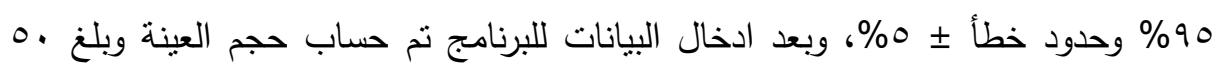


r. قياس متغيرات الدراسة: في ضوء الدراسات السابقة التي إطلع عليها الباحثون، فقد اعتمد الباحثون فى قياس المتغير المستقل (الصريبة على القيمة المضافة ) والمتغير التابع

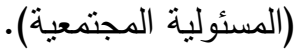
r. أداة تجميع بيانات الدراسة الميدانية: قام الباحثون بتصميم قائمة استقصاء لتجميع البيانات من مفردات البحث، حيث مر إعدادها وتصميمها بالخطوتين التاليتين: الخطوة الأولى: إعداد قائمة الاستقصاء فى صورتها الأولية: قام الباحثون بتصميم قائمة بـات استقصاء أُعدت خصيصاً لقياس متغيرات الدراسة (أثر تطبيق الضريبة على القيمة المضافة الأنياء فى ضوء المسئولية المجتمعية)، وذللك فى ضوء نتائج بعض البحوث والدراسات والكتابات العلمية السابقة، وكذلك فى ضوء ما كثفت عنه نتائج الدراسة الاستطلاعية.

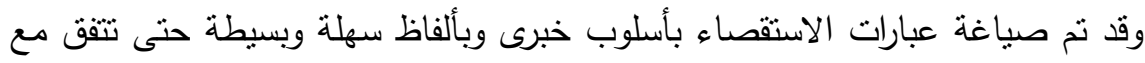
المستوى الثقافي لبعض العاملين والمستقيدين من موضع البحث، هذا وقد بلغ عدد هذه العبارات خمس وخمسون عبارة. الخطوة الثانية: اختبار صدق وثبات الاستقصاء: قام الباحثون بإختبار قائمة الاستقصاء فى عي صورتها المبدئية من خلال التعرف على صدقها وثباتها وذللك على النحو التالى: بلى بلى

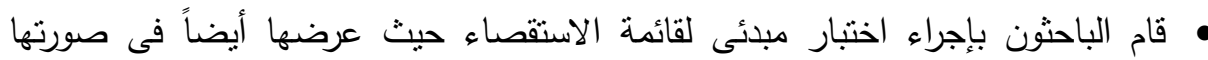
الأولية على عشرين من العاملين بمصلحة الضرائب على المبيعات، وذلك للتأكد من بساطة الصياغة ووضوح اللغة، وللتأكد أيضاً من صلاحية الاستقصاء من الناحية

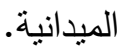
• تم إجراء اختبار ثنات للتأكد من إمكانية الاعتماد على نتائج البحث فى تعميم النتائج،

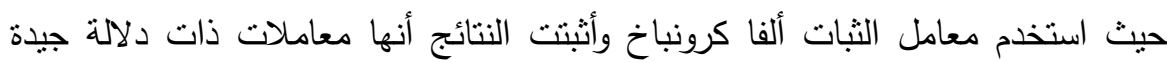
لتحقيق أهداف البحث، ويمكن الاعتماد عليها في تعميم النتائج على مجتمع الدراسة. الخطوة الثالثة: استيفاء بيانات قوائم الاستقصاء واعدادها للتحليل الإحصائى: قام الباحثن

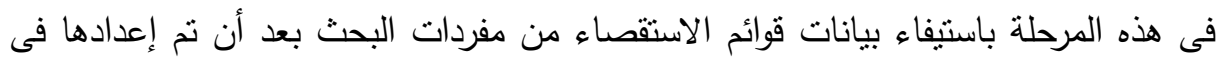

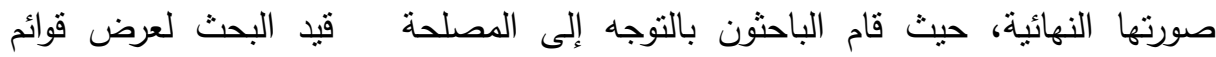


الاستقاء على بعض العاملين والمستقيدين عن طريق المقابلات الثخصية التى أجراها معهم.

هذا كما تم مراجعة قوائم الاستقصاء بعد أن تمت الإجابة عليها، ثم قام الباحثون بإدخال

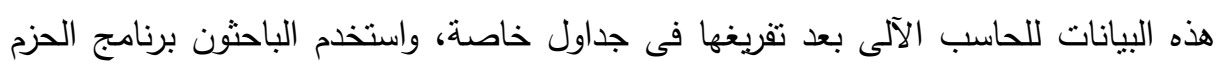
الإحصائية (SPSS) فى إجراء التحليل الإحصائى لبيانات الدراسة الميدانية. ع. أساليب التحليل الإحصائي: اعتمد الباحثون على الأساليب التالية:

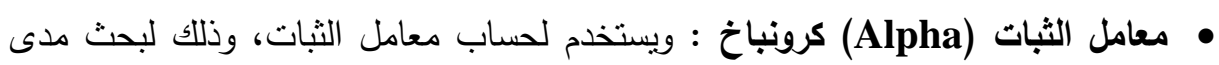
إمكانية الاعتماد على نتائج الدراسة الميدانية في تعميم النتائج. • أسلوب الانحدار المتعدد: ويستخدم لحساب معاملات الانحدار المتعدد المتغير المستقل فئل

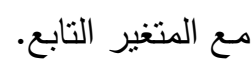
هruskal Walias Test" اختبار كروسكال ـ ولاس : أحد الاختبارات اللامعلمية التي تستخدم لاختبار الفرق بين منوسطين. إن أنسب الاختبارات الإحصائية لهذا الثكل من البيانات هو اختبن لئنار كروسكال ـ ولاس Kruskal Walias Test" القائل بعدم وجود فروق بين الصفوف الثلاثة (عبنة الدراسة) فى استجاباتهم على أسئلة

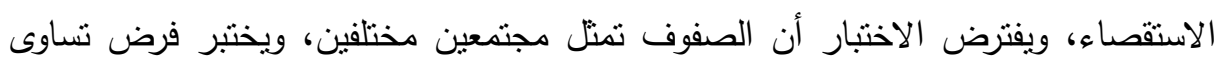

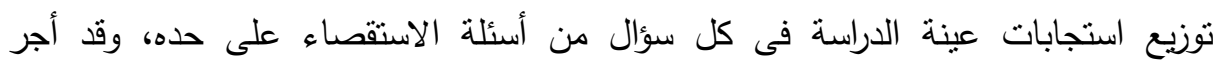

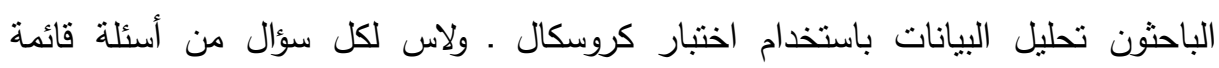
الاستقصاء لاختبار فروض الدراسة. واستخدم الباحثون برنامج الحزم الإحصائية (SPSS) فى إجراء التحليل الإحصائي لبيانات الدراسة الميدانية. 


\section{نئئيج القواسمة}

اختبارات الفروض وتحليل النتائج: ويتتاول الباحث كل عنصر من العناصر السابقة

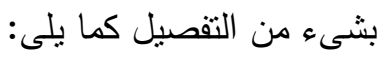
1-حساب معاملي الصدق والثبات: تم إجراء اختبار الثبات (Alpha) لمحتويات قائمة الاستقصاء، للنأكد من إمكانية الاعتماد على نتائج الدراسة الميدانية فى تعميم النتائج،

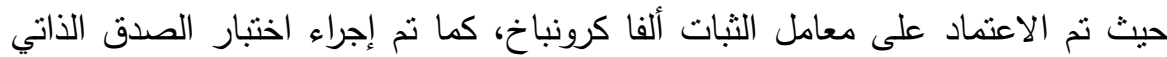
للتأكد من أن عبارات الاستبيان نقيس ما وضعت من أجله وتم حسابه عن طريق إيجاد

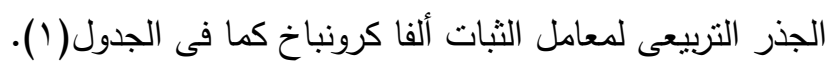
جدول رقم(1 ): معاملى الثبات لألفا كرونباخ والصدق الذاتى لاستمارة الاستقصاء

\begin{tabular}{|c|c|c|c|c|}
\hline معامل الصدق & $\begin{array}{c}\text { معامل الثبات (Alpha) } \\
\text { (A) }\end{array}$ & العبارات & البيـان & المحاور \\
\hline 0.939 & 0.882 & 24 & ضريبة القيمة المضافة & المتغير المستقل \\
\hline 0.976 & 0.952 & 6 & البعد المالى & آولاً \\
\hline 0.987 & 0.975 & 7 & البعد الاجتماعي & ثانيا \\
\hline 0.863 & 0.745 & 6 & بعد النتريعات الضريبية & ثنالثًا \\
\hline 0.971 & 0.943 & 5 & بعد السياسات الضريبية & رابعا \\
\hline 0.915 & 0.838 & 40 & المسئولية المجتمعية & المتغير التابع \\
\hline 0.959 & 0.920 & 6 & المنظور الاقتصادي & أولا \\
\hline 0.958 & 0.918 & 4 & المنظور الاحتماعي & ثنانيا \\
\hline 0.953 & 0.909 & 6 & المنظور القانوني & ثالثا \\
\hline 0.904 & 0.818 & 8 & المنظور البيئي & رابعا \\
\hline
\end{tabular}

المصدر: من إعداد الباحث من واقع مخرجات برنامج (SPSS V25)

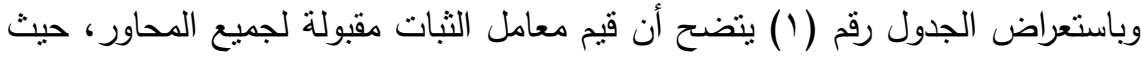
تضمنت استمارة الاستقصاء محورين رئيسيين وكل منظور يتكون من مجموعة من الأبعاد وكل بعد تكون من مجموعة من العبارات تأخذ شكل ليكرت الخماسى، وتراوحت قيمة معامل الثبات بين (0.745) للبعد الثالث من المحور الأول " بعد التشريعات الضريبية " و (0.975)

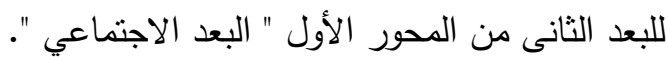


وتراوحت قيمة معامل الصدق الذاتى بين (0.863) للبعد الثالث من المحور الأول "

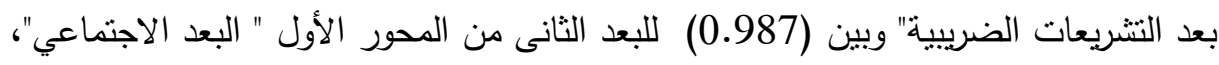

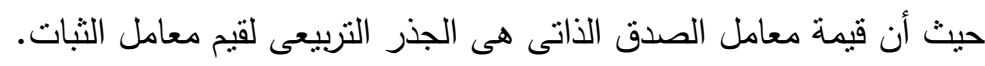

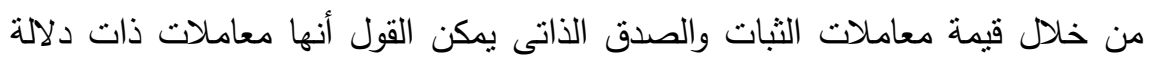
جيدة لتحقيق الهدف من الدراسة ويمكن الاعتماد عليها فى تعميم المخرجات على المجتمع

r-إختبارات الفروض وتحليل النتائج:

1- اختبر الفرض الرئيسي الأول: " لا توجد علاقة ذات دلالة احصائية بين أبعاد ضريبة القيمة المضافة وأبعاد المسئولية المجتمعية في القطاع محل الدراسة.

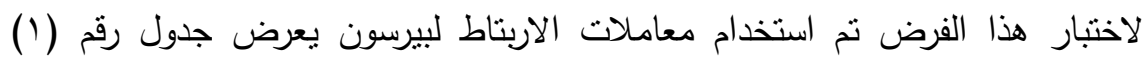
معاملات ارتباط لبيرسون بين أبعاد ضريبة القيمة المضافة (البعد المالي - بعد التشريعات

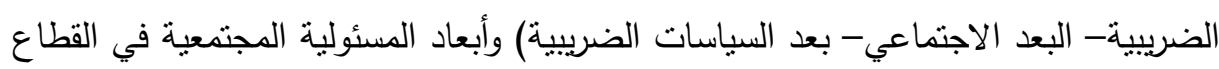
محل الدراسة. جدول رقم(ץ): معاملات ارتباط بين أبعاد ضريبة القيمة المضافة والمسئولية المجتمعية

\begin{tabular}{|c|c|c|c|c|}
\hline بعلد الضياسيات & بعد التشريبية & البعد الاجتماعي & البعد المالي & أبعاد الاراسة \\
\hline $.622 * *$ & .695 ** & $.913^{* *}$ & $.749 * *$ & المنظور الاقتصادي \\
\hline $.811 \% *$ & $.837 * *$ & $.766 * *$ & $.652 * *$ & المنظور الاحتماعي \\
\hline $.782 * *$ & $.621 \% *$ & $.563 * *$ & $.798 * *$ & المنظور القانوني \\
\hline $.821^{* * *}$ & $.637 * *$ & $.715 * *$ & $.811 * *$ & المنظور البيئي \\
\hline
\end{tabular}

1\% * معاملات معنوية عند مستوى معنوية

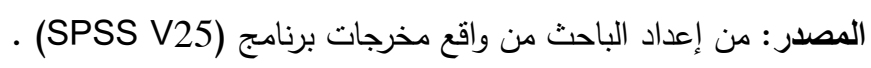

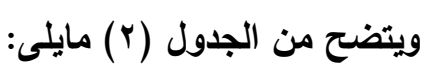

وجود ارتباط طردى قوى بين (البعد الاجتمـاعي) كأحد أبعـاد ضـريبة القيمـة المضـافة مائة

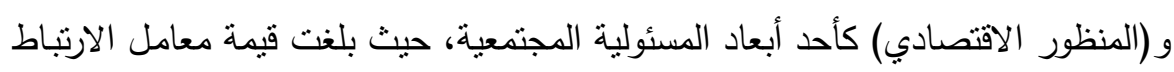

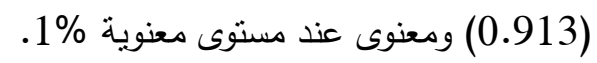


• توجد علاقـة طرديـه قويـة بين (البعد الاجتمـاعي) كأحـد أبعـاد ضـريبة القيمـة المضـافة

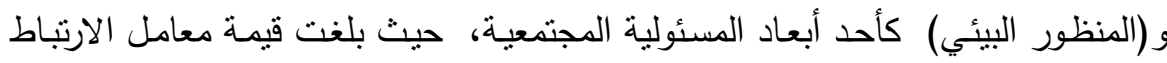

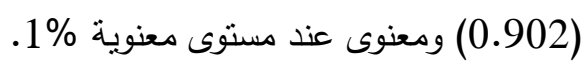

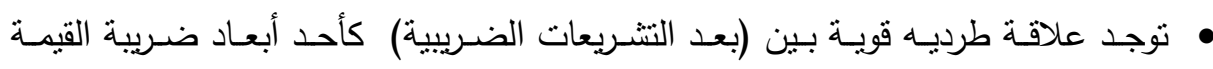

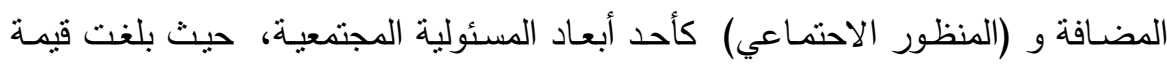

$$
\text { معامل الارتباط (0.837) ومعنوى عند مسنوى معنوية 1\% }
$$

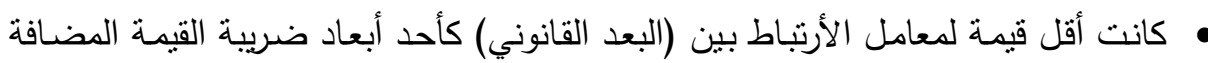

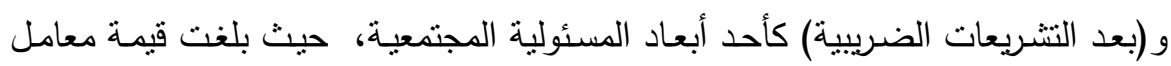
الارتباط ( اYT, • ) مما يدل على وجود علاقة طردية منوسطة بين المتغيرين ومعنوية عند

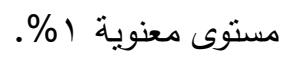

مما سبق يتضح عدم صحة الفرض الرئيسي الأول وصحة الفرض البديل: " توجد علاقة

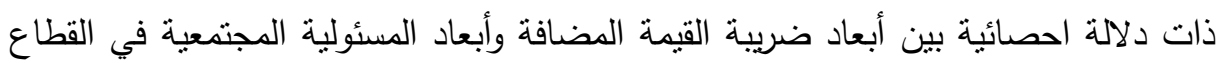
محل الدراسة. r - اختبار الفرض الرئيسي الثاني: لا يوجد ناثيراً معنوياً لأبعاد ضريبة القيمة المضافة علي أبعاد المسئولية المجتمعية في القطاع محل التطبيق. لاختبار هذا الفرض تم اختبار الفروض الفرعية التالية: الفرض الفرعى الأول من الفرض الرئيسي الثاني: لا يوجد ناثيراً معنوياً لأبعاد ضريبة القيمة الفئه

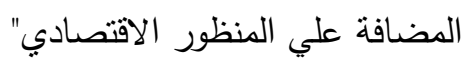
لاختبار هذا الفرض نم استخدام الإنحدار المتدرج لتحديد اهم أبعاد ضريبة القيمة المضافة كمتغيرات مستقلة نؤثرفى المتغير التابع (متوسط آراء عينة الدراسة حول المنظور الإندار

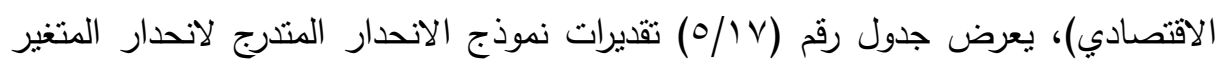

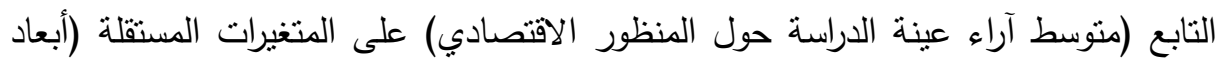


محمد أحمد على أحمد وآخرون

جدول رقم(ץ): تقديرات نموذج الانحدار المتدرج على المنظور الاقتصادي

\begin{tabular}{|c|c|c|c|c|c|c|}
\hline \multicolumn{4}{|c|}{ التقديرات } & \multirow{2}{*}{ المستقلئة فى المتوذج } & \multirow{2}{*}{$\begin{array}{c}\mathbf{F} \\
\text { (sig.) }\end{array}$} & \multirow{2}{*}{$\begin{array}{l}\text { التحديد } \\
\text { R2 }\end{array}$} \\
\hline Sig. & $t$ & $\beta$ & & & & \\
\hline 2.000 & 8.185 & 1.186 & الثنابت & \multirow{3}{*}{$\begin{array}{c}x 7.13 \\
\times 14.19\end{array}$} & \multirow{3}{*}{$\begin{array}{c}232.522 \\
(0.000)\end{array}$} & \multirow{3}{*}{0.594} \\
\hline .000 & 9.100 & .355 & $\times 7.13$ & & & \\
\hline .000 & 6.286 & .320 & $\times 14.19$ & & & \\
\hline
\end{tabular}

المصدر: من إعداد الباحث من واقع مخرجات برنامج (SPSS V25) .

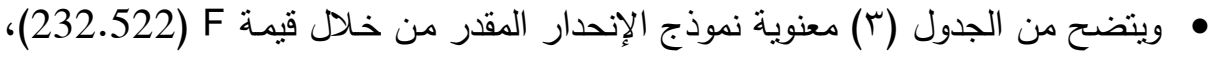

وقيمة(sig=0.000) ، كما يتضح معنوية معاملات الانحدار والحد الثابت من خلال قيم

t وقيم (sig)، عند مستوى معنوية 5\%.

• ويتضح من الجدول (r) أيضاً ان أهم أبعاد ضريبة القيمة المضافة التى تؤثر فى المنظور

الاقتصادي فى إدارة القطاع محل الدراسة هى:

$$
\text { • • البعد الاجتماعي التشريعات الضريبية }
$$

وبلغت قيمة معامل التحديد (0.594) مما بدل على ان المتغيرات المستقلة تفسر

59.4\% من التغيرات التى تحدث فى المتغير التابع (متوسط آراء العينة حول المنظور

(الاقتصادي).

مما سبق يتضح عدم صحة الفرض الفرعى الأول من الفرض الرئيسي الثاني وصحة

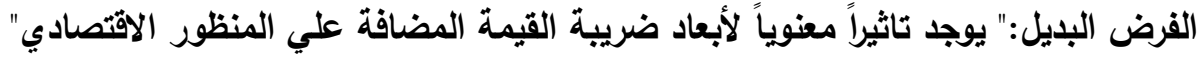

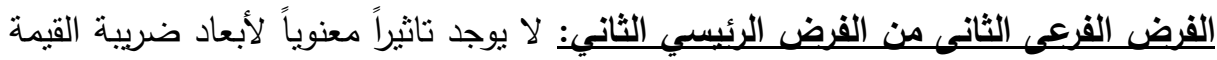

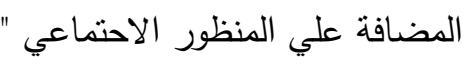

لاختبار هذا الفرض تم استخدام الإنحدار المتدرج لتحديد اهم أبعاد ضريبة القيمة

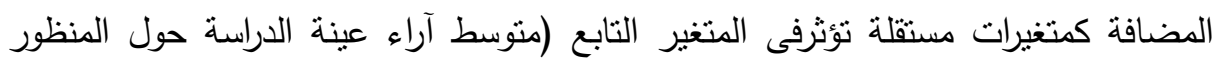

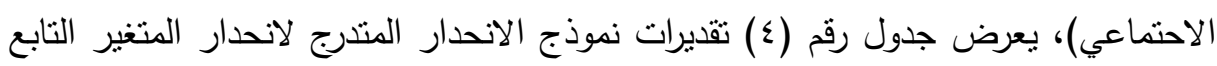

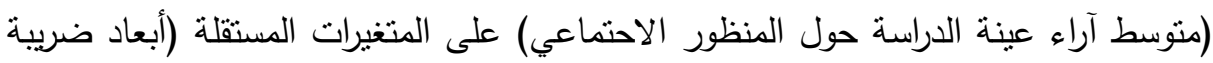

القيمة المضافة)

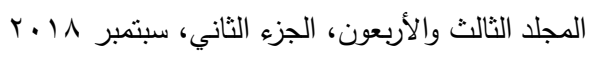




\begin{tabular}{|c|c|c|c|c|c|c|}
\hline \multicolumn{4}{|c|}{ التقديرات } & \multirow{2}{*}{ المتغيرات النموذجتقلة } & \multirow{2}{*}{$\begin{array}{c}F \\
\text { (sig.) }\end{array}$} & \multirow{2}{*}{ التحديد معامل R2 } \\
\hline Sig. & $t$ & $\beta$ & & & & \\
\hline .002 & 3.163 & .675 & الثابت & \multirow{4}{*}{$\begin{array}{c}\times 7.13 \\
\times 20.24 \\
\times 1.6\end{array}$} & 99.55 & \multirow{4}{*}{0.485} \\
\hline .000 & 6.435 & .305 & $\times 7.13$ & & 0 & \\
\hline .000 & 4.220 & .311 & $\times 20.24$ & & $(0.00$ & \\
\hline .005 & 2.838 & .201 & $\times 1.6$ & & 0) & \\
\hline
\end{tabular}

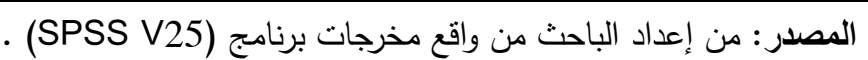

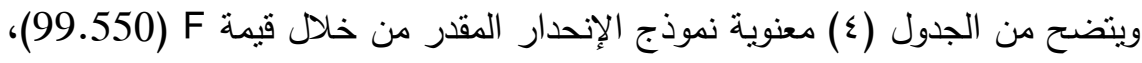

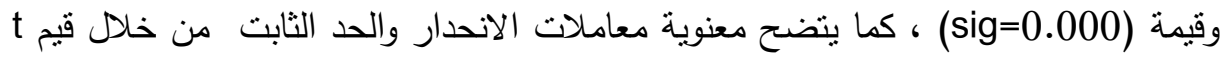

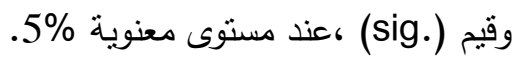

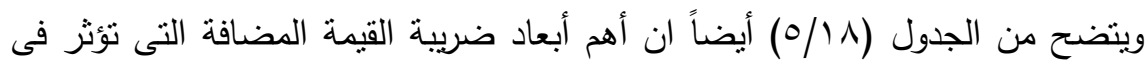

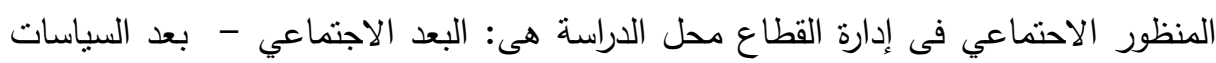

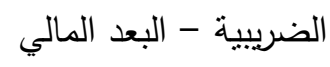

وبلغت قيمة معامل التحديد (0.485) مما يدل على ان المتغيرات المستقلة تفسر

48.5\% من التغيرات التى تحدث فى المتغير التابع (متوسط آراء العينة حول المنظور

$$
\text { الاحتماعي). }
$$

مما سبق يتضح عدم صحة الفرض الفرعى الثانى من الفرض الرئيسي الثاني وصحة

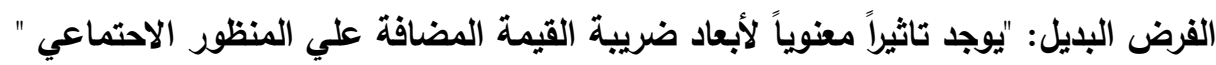
الفرض الفرعى الثالث من الفرض الرئيسي الثاني: لا يوجد تاثيراً معنوياً لأبعاد ضريبة القيمة لائية المضافة علي المنظور القانوني ".

لاختبار هذا الفرض تم استخدام الإنحدار المتدرج لتحديد اهم أبعاد ضريبة القيمة

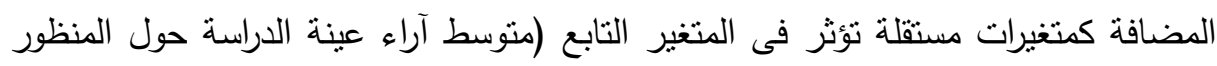
القانوني)، يعرض جدول رقم (ך) نقديرات نموذج الانحدار المتدرج لانحدار المتغير التابع (متوسط آراء عينة الدراسة حول المنظور القانوني) على المتغيرات المستقلة (أبعاد ضريبة القيمة المضافة) 
محمد أحمد على أحمد وآخرون

جدول رقم(•): تقديرات نموذج الانحدار المتدرج على المنظور القانوني

\begin{tabular}{|c|c|c|c|c|c|c|}
\hline \multicolumn{4}{|c|}{ التقديرات } & \multirow{2}{*}{ فتغيرات النموذج المستلة } & \multirow{2}{*}{$\begin{array}{c}\mathbf{F} \\
(\text { sig. })\end{array}$} & \multirow{2}{*}{$\begin{array}{l}\text { التحعاميد } \\
\text { R2 }\end{array}$} \\
\hline Sig. & $\mathbf{t}$ & $\beta$ & & & & \\
\hline .000 & 6.216 & .634 & الثابت & \multirow{5}{*}{$\begin{array}{c}\times 20.24 \\
\times 1.6 \\
\times 7.13 \\
\times 14.19\end{array}$} & \multirow{5}{*}{$\begin{array}{c}339.74 \\
8 \\
(0.000)\end{array}$} & \multirow{5}{*}{0.811} \\
\hline .000 & 12.707 & .509 & $\times 20.24$ & & & \\
\hline .000 & 9.526 & .317 & $\times 1.6$ & & & \\
\hline .000 & 6.427 & .169 & $\times 7.13$ & & & \\
\hline .000 & 3.531 & .128 & $\times 14.19$ & & & \\
\hline
\end{tabular}

المصدر: من إعداد الباحث من واقع مخرجات برنامج (SPSS V25) .

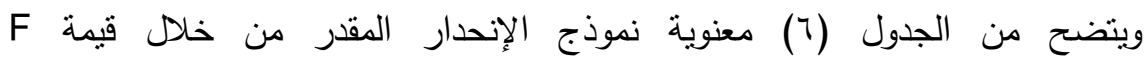

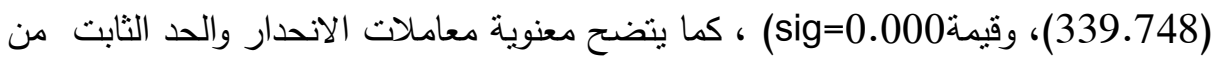

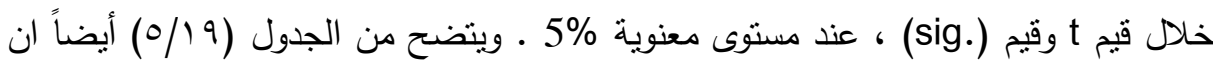

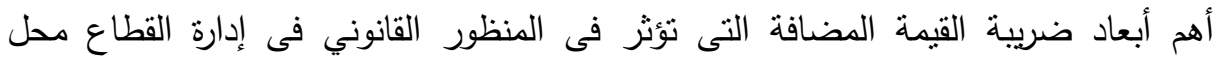

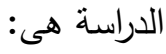

$$
\begin{aligned}
& \text { 1-بعد السياسات الضريبية - ب-البعد المالي } \\
& \text { r-البعد الاجتماعي - ع - بعد التشريعات الضريبية }
\end{aligned}
$$

وبلغت قيمة معامل التحديد (0.811) مما يدل على ان المتغيرات المستقلة تفسر 81.1\% من التغيرات التى تحدث فى المتغير التابع ( متوسط آراء العينة حول المنظور القانوني).

مما سبق يتضح عدم صحة الفرض الفرعى الثالث من الفرض الرئيسي الثاني وصحة

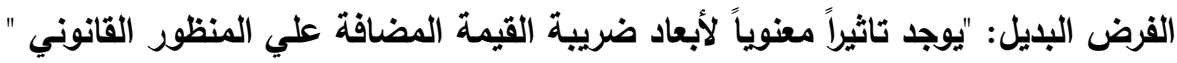

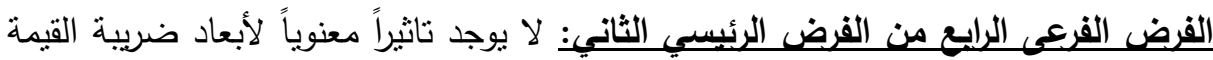

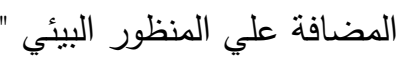
لاختبار هذا الفرض نم استخدام الإنحدار المتدرج لتحديد اهم أبعاد ضريبة القيمة المضافة كمتغيرات مستقلة تؤثرفى المتغير التابع (متوسط آراء عينة الدراسة حول المنظور البيئي)، يعرض جدول رقم (•/\%) تقديرات نموذج الانحدار المتدرج لانحدار المتغير التابع 
(متوسط آراء عينة الدراسة حول المنظور البيئي) على المتغيرات المستقلة (أبعاد ضريبة القيمة

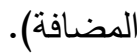

جدول رقم(†): تقديرات نموذج الانحدار المتدرج على المنظور البيئي

\begin{tabular}{|c|c|c|c|c|c|c|}
\hline \multicolumn{4}{|c|}{ التقديرات } & \multirow{2}{*}{ 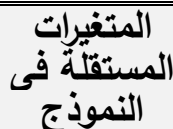 } & \multirow{2}{*}{$\begin{array}{c}\mathbf{F} \\
(\text { sig. })\end{array}$} & \multirow{2}{*}{$\begin{array}{l}\text { التحديد } \\
\text { R2 } \\
\text { R2 }\end{array}$} \\
\hline Sig. & $t$ & $\beta$ & & & & \\
\hline .000 & 4.944 & .539 & الثابت & \multirow{3}{*}{$\begin{array}{c}\times 7.13 \\
\times 20.24\end{array}$} & \multirow{3}{*}{$\begin{array}{c}840.897 \\
(0.000)\end{array}$} & \multirow{3}{*}{0.841} \\
\hline .000 & 26.922 & .604 & $\times 7.13$ & & & \\
\hline .000 & 7.764 & .265 & $\times 20.24$ & & & \\
\hline
\end{tabular}

المصدر: من إعداد الباحث من واقع مخرجات برنامج (SPSS V25) .

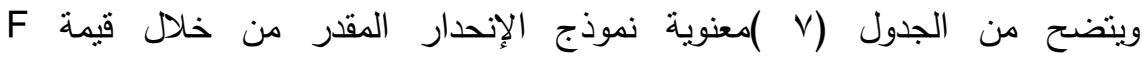

(840.897)، وقيمة(sig=0.000) ، كما يتضح معنوية معاملات الانحدار والحد الثابت مندونج

من خلال قيم tوقيم(sig) ، عند مسنوى معنوية 5\%.

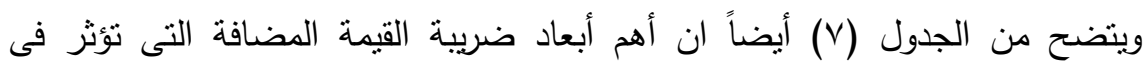

المنظور البيئي فى إدارة القطاع محل الدراسة هى:

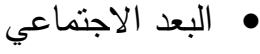

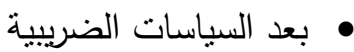

وبلغت قيمة معامل التحديد (0.841) مما يدل على ان المتغيرات المستقلة تفسر

84.1\% من التغيرات التى تحدث فى المتغير التابع (متوسط آراء العينة حول المنظور

(البيئي).

مما سبق يتضح عدم صحة الفرض الفرعى الرابع من الفرض الرئيسي الثاني وصحة

الفرض البديل:" يوجد تاثيراً معنوياً لأبعاد ضريبة القيمة المضافة علي المنظور البيئي " ويتضح مما سبق عدم صحة الفرض الرئيسي الثاني وصحة الفرض البديل: " يوجد تاثيراً

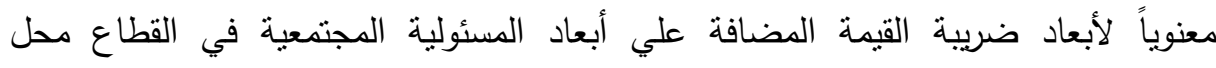

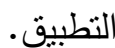




\section{المتيائم}

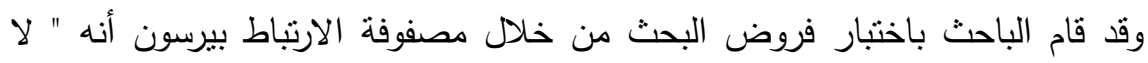
توجد علاقة ذات دلالة احصائية بين أبعاد ضريبة القيمة المضافة وأبعاد المسئولية المجتمعية

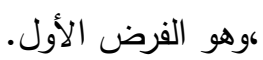

أما الفرض الأول والثانى: وهو الفرض الرئيسى للبحث فقد نبين أيضاً من خلال الإنحدار المتعدد أنه توجد علاقة ذات معنوية موجبة تبين إيجابية نطبيق الأسلوب المقترح

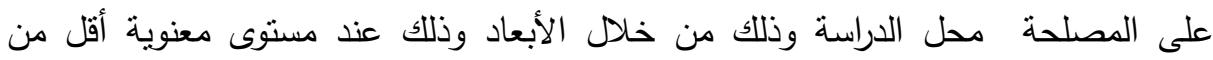

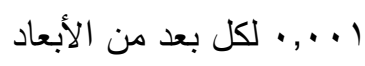
وذلك كما يلى:

• تبين أن المتغير المسنقل (الضريبة على القيمة المضـافة) توجد علاقة طرديـ قويـة بين (بعد التشريعات الضريبية) كأحد أبعاد ضريبة القيمة المضافة و (المنظور الاحتماعي)

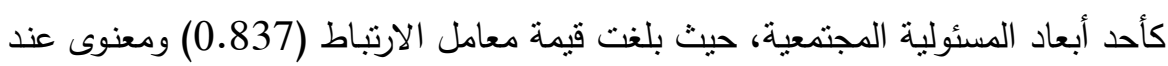

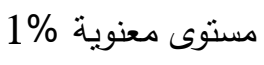

• كانت أقل قيمة لمعامل الارتباط بين (البعد القانوني) كأحد أبعاد ضريبة القيمة المضافة

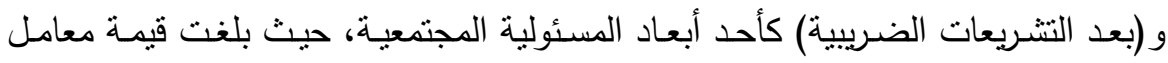
الارتباط (T T T, •) مما يدل على وجود علاقة طردية متوسطة بين المتغيرين ومعنوية عند

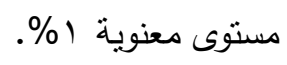

مما سبق يتضح عدم صحة الفرض الرئيسي الأول وصحة الفرض البديل: " نوجد علاقة

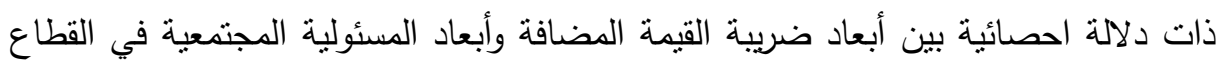
محل الدراسة. مما سبق يتبين إيجابية تطبيق الضريبة على القيمة المضافة فى محل الدراسة.

\section{تموسيايت التراسة}

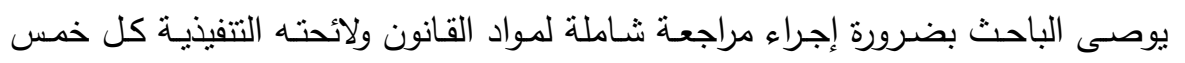
سنوات علي الأقل حتي تواكب المتغيرات الإقتصادية والإجتماعية المختلفة. 
• إصدار قانون موحد للإجراءات الضريبية حيث أن هناك حاجة إلى توحيد الإجراءات بين

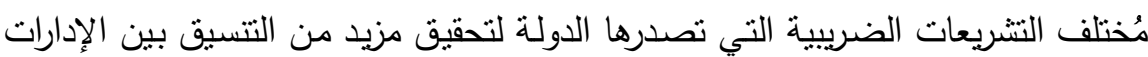

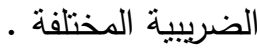
• ضرورة إعادة النظر في الفترة الضريبية التى يقدم عنها الاقرار بأن يكون توريد الضريبة شهرياً وأن يقدم الاقرار ربع سنوي أو نصف سنوي أو سنوي حسب كل طبيعة وحجم كل

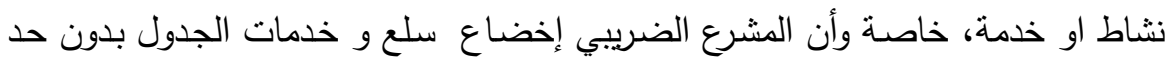

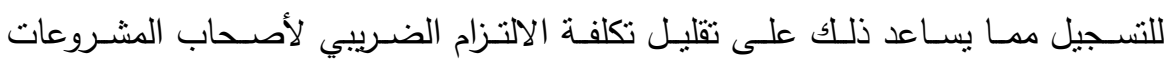

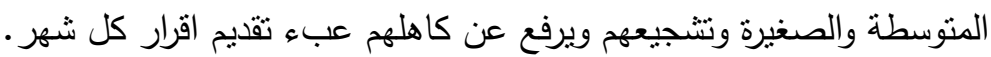

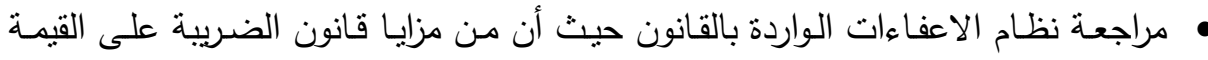

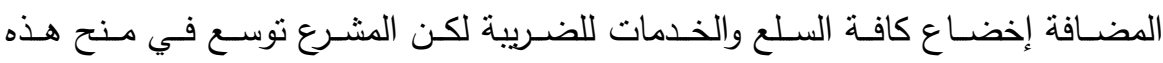
الاعفاءات، مـع ضـرورة تقرير نظام فعـال بديل للاجور ودعم محدودى الدخل والفقراء

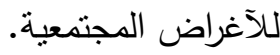
• العمل على مراجعة حد التسجيل كل ثلاثة أعوام مراعاة لظروف التضخم

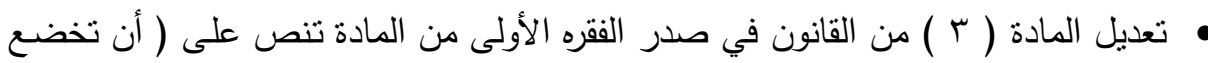

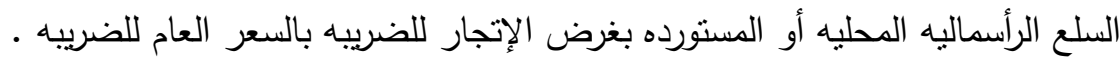

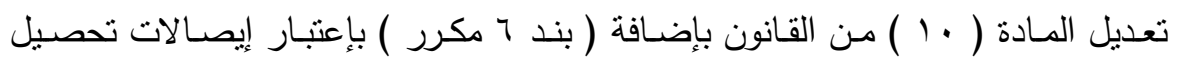

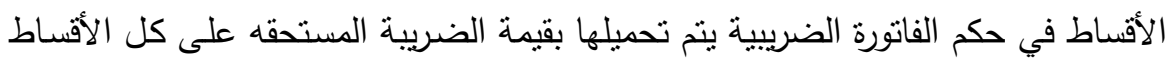

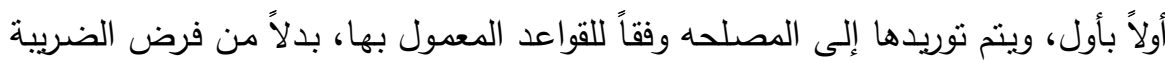

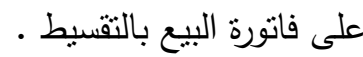
• تعديل المادة ( T ) من القانون بحيث يسمح للمسجل بخصم ما يلي: كافة الضرائب المسدده على المدخلات سواء كانت خاضعه للضريبه على القيمة المضافه

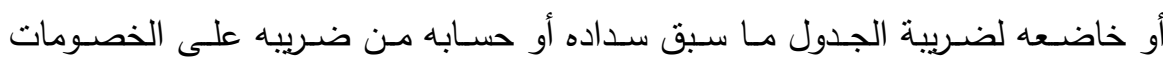
والتعويضات التي يتم منحها للموزعين سواء كانت نقدية أو في شكل بضائع . 
خصم الضريبة على أجزاء الآلات والمعدات وقطع الغيار المستخدمه في الإنتاج أسوه

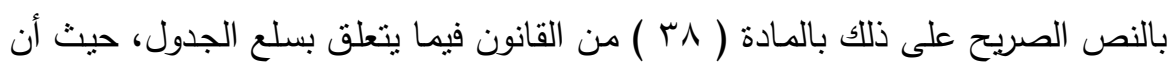
جوهر الضريبة على القيمة المضـافة يكمن في نظام الخصم ومن ثم يجب تعميم نظام الخصم الضريبي بقدر الإمكان.

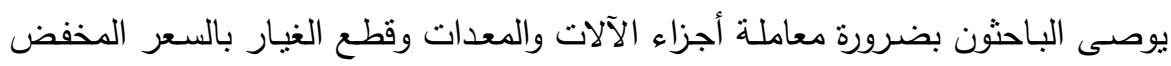

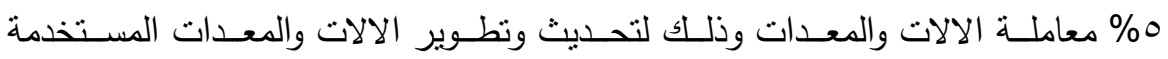

$$
\text { بالانتاج. }
$$

\section{المراليج}

جلال الثافعي(V ا • r): "إطار مقترح لتطبيق نظام الضريبة على القيمة المضافة الثامل في مصر "كلية التجارة، جامعة الزقازيق.

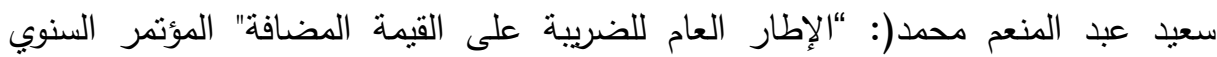

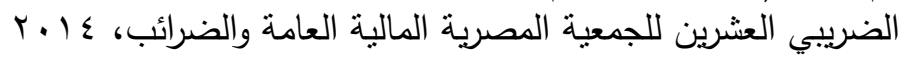

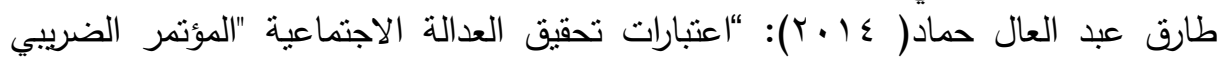

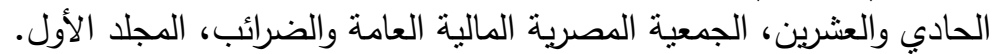

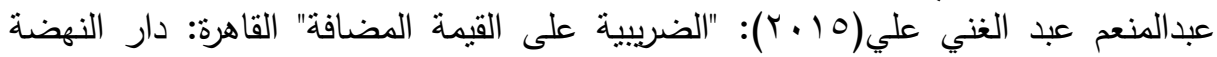

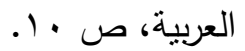

غنيم،عثمان محمد "إثكالية التنمية المستدامة في ظل الثقارة التقافة الاقتصادية السائدة"، دراسات

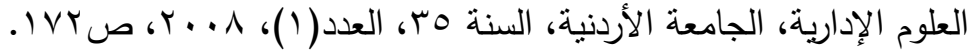

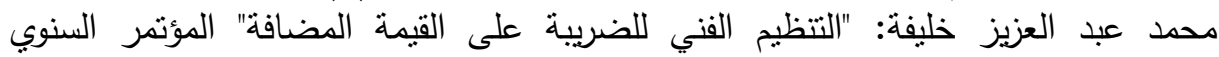

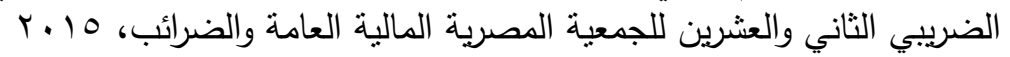

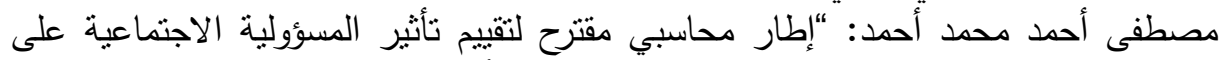

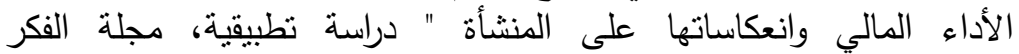

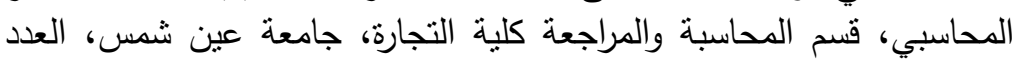

$$
\text { r. إبريلّ (1) }
$$

G. Caldwell, "The value- Added Tax: A new tax system for the united states: united states of Anerican, ISB No 944848-001,(November 8, 2011), pp 146-147

G. Caldwell, "The value- Added Tax: A new tax system for the united states: united states of Anerican, ISB No 944848-00-1, (November 8, 2013), pp 146-147.

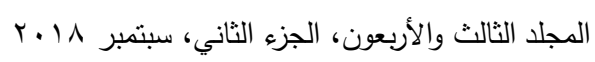


J.M . Bickley, Value-Added Tax: A new U.S Revenue Source ? ,Congressional Research Service (CRS), The Library of Congress, (August 22,2011).

L .p. ZABOV," Comparison between Sales Tax and Value Added Tax", Affiliation unknown, (Dec., 1,2012).

Mclure ,"Coordinating State sales Taxes With A Federaal VAT Opportunities, Risks and Challenges' 'Stanford University .The Hoover Institution on War, Revolution and Peace, national Bureau of Economic Research (NBER),State Tax Notes ,V01. 36,no.12(June 20,2011).

Wang, y,(2011) Corporate Social Responsibility and Stock Performance- Evidence From Taiwan Modem Economy,Nov,pp.788-799

WOrid Business Council For Sustainable Development' Corporate Social Responsibility ;Meeting Changing Expectation “ WBCSD First Report on Corporate Social Responsibility Grenove, 199. 
محمد أحمد على أحمد وآخرون

\title{
A PROPOSED FRAMEWORK FOR APPLYING THE VALUE ADDED IN LIGHT OF SOCIETAL RESPONSIBILITY - A FIELD STUDY
}

\author{
Ahmed, M. A. A. ${ }^{(1)}$; Hammad, T. A. ${ }^{(2)}$; Khalifa, M. A. ${ }^{(2)}$ \\ and Abdel Basit, W. F. ${ }^{(2)}$ \\ 1) Institute of Environmental Studies \& Research, Ain Shams \\ University 2) Faculty of Commerce, Ain Shams University
}

\begin{abstract}
This study drives at measuring impact of the value added on societal responsibility, especially, its application in Egypt. The study also drives at identifying the importance and mechanisms of applying this tax, added to that establishing an applied study for identifying the appropriateness of this taxation to demands and potentials in Egypt and the suggested bases for this implementation. For achieving this study objectives, a questionnaire form is designed and collected through interview, including as well a set of phrases that measure attitudes of the study sample towards study variables. The researchers count in this study on mixture between deductive and inductive methods across the study theoretical and field study approach. They have administered a content analysis of data using Kruskal -Wallis K Test for each question in the investigation list for testing study hypotheses using the study sample consisting of (50) items as the correct retrieved forms. researchers come to several results and recommendations that can be applied to the study examined institution (Egyptian Tax Authority).

The study comes to that "there are economic benefits for applying the value added in Egypt including the increase of taxation outcome, increase of those taxpayers and achieving more societal responsibility for all society parties".
\end{abstract}

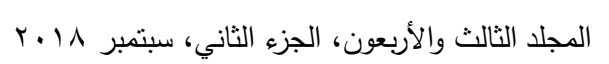




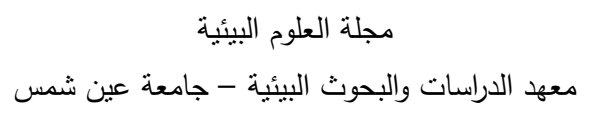

\section{The study recommends the following:}

- The researcher recommends the necessity for holding a total review of the law items and its executive legislation every five years at least in order to cope with economic and social changes.

- Issuing a unified law for tax procedures as there is a critical need for unifying procedures in different tax legislations issued by the state for achieving more coordination between various tax administrations. 